\title{
KARAKTERISTIK DAN SKRINING FITOKIMIA EKSTRAK ETANOL 70\% BATANG KEPUH (Sterculia foetida L.)
}

\author{
N. P. S. E. Cahyani", J. Susiarni, K. C. S. Dewi, N. L. P. Melyandari, \\ K. W. A. Putra, D. A. Swastini \\ Program Studi Farmasi Fakultas Matematika dan Ilmu Pengetahuan Alam Universitas Udayana \\ Jalan Kampus Unud-Jimbaran, Jimbaran-Bali, Indonesia 80364 Telp/Fax: 0361-703837 \\ *E-mail: syntiacahyani@gmail.com
}

\begin{abstract}
ABSTRAK
Kepuh (Sterculia foetida L) merupakan tanaman sejenis kapuk yang secara ilmiah telah terbukti mempunyai aktivitas sebagai anti inflamasi dan analgesik.. Ekstrak etanol $70 \%$ batang kepuh diperoleh dengan cara maserasi menggunakan etanol 70\%. Pemeriksaan karakteristik ekstrak etanol $70 \%$ batang kepuh meliputi pemeriksaan organoleptis, kadar air dan penetapan kadar sisa pelarut. Skrining fitokimia terhadap ekstrak etanol 70\% kulit batang kepuh meliputi pemeriksaan alkaloid, flavonoid, saponin, tannin dan polifenol, serta glikosida. Hasil karakteristik ekstrak etanol 70\% batang kepuh diperoleh kadar air 8,66 $\pm 0,748 \%$, sisa pelarut memiliki kadar etanol 0 (nol). Hasil skrining fitokimia menunjukkan ekstrak etanol $70 \%$ batang kepuh mengandung senyawa steroid, triterpenoid, flavonoid, saponin, tannin dan polifenol. Identifikasi menggunakan spektrofotometri UV-Vis menghasilkan $\lambda 212 \mathrm{~nm}$, absorbansinya sebesar 1,8601 dan $\lambda 284 \mathrm{~nm}$, absorbansinya sebesar 0,42186 .
\end{abstract}

Kata Kunci : Sterculia foetida, karakteristik, skrining fitokimia

\section{ABSTRACT}

Kepuh (Sterculia foetida L) is a type of kapok plant that has been scientifically proven to have activity as an anti-inflammatory and analgesic. $70 \%$ ethanol extract of stem stem is obtained by maceration using $70 \%$ ethanol. Examination of the characteristics of $70 \%$ ethanol extract of kepuh stem included organoleptic, of moisture content and determination of residual solvent content. Phytochemical screening of $70 \%$ ethanol extract of kepuh bark includes: alkaloid, flavonoid, saponin, tannin, polyphenol, and examination of glycosides. The results of the examination of the characteristics of $70 \%$ ethanol extract of kepuh stem obtained water content of $8.66 \pm 0.748 \%$, the residual content of the solvent had a 0 (zero) ethanol level. The results of phytochemical screening showed $70 \%$ ethanol extract of stem stem containing steroid compounds, triterpenoids, flavonoids, saponins, tannins and polyphenols. The identification using UV-Vis spectrophotometry produced $\lambda 212 \mathrm{~nm}$ with absorbance of 1.8601 and $\lambda 284 \mathrm{~nm}$ with absorbance of 0.42186 .

Keywords : Sterculia foetida, characteristic, phytochemical screening

\section{PENDAHULUAN}

Kepuh atau dikenal juga dengan pohon genderuwo merupakan tanaman sejenis kapuk yang banyak tumbuh di hutan dan tempat-tempat yang kering. Kepuh di Indonesia memiliki banyak sebutan antara lain halumpang (Batak), kepoh, koleangka (Sunda), kepuh, kepoh, jangkang (Jawa), jangkang, kekompang (Madura), kepuh, kepah, kekapahan (Bali), kepoh, kelompang, kapaka, wuka, wukak (NTT), bungoro, kalumpang (Makassar), alumpang, alupang, kalupa (Bugis), kailupa furu, kailupa buru (Herdiana, 2005).

Tanaman Kepuh (Sterculia foetida $\mathrm{L}$ ) dapat mempunyai tinggi mencapai $40 \mathrm{~m}$ dan diameter antara 90-120 cm. Kepuh mempunyai pohon yang tinggi dan lurus, bercabang. Daunnya berbentuk majemuk menjari, mempunyai tangkai $12,5-23 \mathrm{~cm}$, bunganya berkelamin satu, berumah satu biasanya terdapat pada ketiak daun yang masih muda dan mengeluarkan bau busuk. Bentuk bunga majemuk tersusun dalam malai dekat ujung ranting, panjang 10-15 cm, buah Kepuh 
berukuran relatif besar, berwarna hijau jika masih muda setelah matang berubah menjadi merah, kadang-kadang hitam dan membuka (Suwandi, 2013).

Tanaman kepuh banyak digunakan oleh masyarakat sebagai obat tradisional dalam menyembuhkan beberapa macam penyakit seperti rematik, TBC, dan pusing. Secara ilmiah tanaman kepuh telah terbukti mempunyai aktivitas sebagai antiinflamatorry dan analgesik (Maryanti, 2014).

Efek terapetik yang ditimbulkan oleh tanaman kepuh diakibatkan karena adanya kandungan metabolit yang terkandung di dalamnya, baik metabolit primer maupun sekunder. Kandungan kimia dalam tanaman berperan penting terhadap aktivitas biologis dari tanaman tersebut (Hayne, 1987).

Berdasarkan latar belakang tersebut perlu dilakukan pemeriksaan karakteristik dan skrining fitokimia ekstrak etanol $70 \%$ batang kepuh (Sterculia foetida L.) untuk mengetahui golongan senyawa apa saja yang terkandung di dalam ekstrak kulit batang kepuh.

\section{MATERI DAN METODE}

Bahan

Bahan yang digunakan dalam penelitian yaitu batang kepuh diperoleh dari Kabupaten Gianyar. Pelarut kimia yang digunakan yaitu etanol $70 \%, \mathrm{HCl} 2 \mathrm{~N}$, pereaksi Mayer, pereaksi Dragendrof, asam borat, asam oksalat, aseton, larutan besi (III) klorida 10\%, asam asetat anhidrat, asam asetat glacial dan kloroform.

\section{Peralatan}

Alat-alat yang digunakan dalam penelitian : beaker glass, cawan porselin, gelas ukur, batang pengaduk, tabung reaksi, pipet tetes, desikator, botol timbang, seperangkat alat destilasi.

\section{Cara Kerja}

\section{Ekstraksi Serbuk Batang Kepuh (Sterculia foetida $L$.)}

Ekstrak etanol $70 \%$ batang kepuh dibuat dengan cara maserasi menggunakan etanol $70 \%$ perbandingan 1:1. Serbuk kering batang kepuh sebanyak 100 gram dimasukkan ke dalam bejana maserasi, dan ditambahkan dengan 100 mililiter etanol 70\%. Campuran tersebut direndam selama 6 jam sambil sesekali diaduk, kemudian didiamkan selama
24 jam. Maserat selanjutnya dipisahkan dan proses diulangi 2 kali dengan jenis dan jumlah pelarut yang sama. Semua maserat dikumpulkan dan diuapkan dengan rotary evaporator pada suhu $60^{\circ} \mathrm{C}$ dengan kecepatan putar $60 \mathrm{rpm}$ hingga diperoleh ekstrak yang dapat dituang dan masih mengandung pelarut dalam volume yang sedikit. Penguapan pelarut ekstrak dilanjutkan dengan menggunakan oven atau pemanasan pada waterbath dengan suhu $60^{\circ} \mathrm{C}$ hingga diperoleh ekstrak kental.

\section{Pemeriksaan Karakteristik Ekstrak}

\section{Pemeriksaan Organoleptis}

Pemeriksaan organoleptis dilakukan secara visual terhadap ekstrak dengan pemeriksaan warna dan bau

\section{Pemeriksaan Kadar Air}

Penetapan kadar air dari ekstrak etanol $70 \%$ batang kepuh dilakukan dengan metode gravimetri. Lebih kurang 1 gram ekstrak ditimbang ,kemudian dikeringkan dalam oven pada suhu $105^{\circ} \mathrm{C}$ selama 30 menit. Kemudian dinginkan dalam desikator dan ditimbang. Selanjutnya dilakukan pemanasan kembali dalam oven selama 30 menit, dinginkan dalam desikator dan ditimbang kembali sampai didapatkan berat konstan (Depkes RI, 1989).

\section{Penetapan Kadar Sisa Pelarut}

Penetapan kadar sisa pelarut dilakukan untuk mengetahui sisa pelarut etanol yang masih ada dalam ekstrak. Tujuannya untuk memberikan jaminan bahwa selama proses ekstraksi tidak meninggalkan sisa pelarut yang memang seharusnya tidak boleh ada, serta sebagai parameter agar ekstrak tersebut layak untuk di formulasikan (Depkes RI, 2000). Timbang sejumlah 2,0 gram ekstrak kental dilarutkan dalam air sampai 25,0 mL kemudian dimasukkan kedalam labu destilasi. Atur suhu destilat pada $78,5^{\circ} \mathrm{C}$. Catat destilasi hingga diperoeh destilat lebih kurang $2 \mathrm{~mL}$ lebih kecil dari volume cairan uji (destilasi selama 2 jam atau tidak menetes lagi). Tambahkan air sampai volume 25,0 mL. Tetapkan bobot jenis cairan pada suhu $25^{\circ} \mathrm{C}$ seperti yang tertera pada penetapan bobot jenis. Hitung persentase volume dari etanol dalam cairan menggunakan Tabel bobot jenis dan kadar etanol pada Farmakope Indonesia Edisi IV (Khoiraini, 2013). 


\section{Skrining Fitokimia}

Uji fitokimia pada ekstrak batang kepuh meliputi pemeriksaan alkaloid, flavonoid, saponin, tannin, polifenol, glikosida, steroid, dan triterpenoid.

\section{Pembuatan Larutan Uji}

Pembuatan larutan uji untuk skrining fitokimia dilakukan dengan melarutkan 500 mg ekstrak etanol 70\% Batang Kepuh (Sterculia foetida L.) dalam $50 \mathrm{~mL}$ etanol $70 \%$

\section{Pemeriksaan Alkaloid}

Sebanyak $2 \mathrm{~mL}$ larutan ekstrak uji diuapkan diatas cawan porselin hingga diperoleh residu. Residu kemudian dilarutkan dengan $5 \mathrm{~mL} \mathrm{HCl} 2 \mathrm{~N}$. Larutan yang didapat dibagi menjadi 3 tabung reaksi. Tabung pertama ditambahkan dengan aquadest yang berfungsi sebagai blanko. Tabung kedua ditambahkan pereaksi Dragendroff sebanyak 3 tetes dan tabung ketiga ditambahkan pereaksi Mayer sebanyak 3 tetes. Terbentuknya endapan jingga pada tabung kedua dan endapan kuning pada tabung ketiga menunjukkan adanya alkaloid (Farnsworth, 1966).

\section{Pemeriksaan Flavonoid}

$1 \mathrm{~mL}$ larutan uji, dibasahkan sisanya dengan aseton, tambahkan sedikit serbuk halus asam borat dan serbuk halus asam oksalat, panaskan hati-hati diatas penangas air dan hindari pemanasan berlebih. Campur sisa yang diperoleh dengan $10 \mathrm{~mL}$ eter . Amati dengan sinar UV 366 nm: larutan berflouresensi kuning intensif, menunjukkan adanya flavonoid (Depkes RI, 1989).

\section{Pemeriksaan Saponin}

$10 \mathrm{~mL}$ larutan ekstrak uji dalam tabung reaksi dikocok vertikal selama 10 detik kemudian dibiarkan selama 10 detik. Pembentukan busa setinggi $1-10 \mathrm{~cm}$ yang stabil selama tidak kurang 10 menit, menunjukkan adanya saponin. Pada penambahan 1 tetes $\mathrm{HCl} 2 \mathrm{~N}$, busa tidak hilang (Depkes RI, 1995).

\section{Pemeriksaan Tanin dan Polifenol}

$3 \mathrm{~mL}$ larutan ekstrak uji dibagi kedalam 3 bagian yaitu tabung $\mathrm{A}$, tabung $\mathrm{B}$, dan tabung C. Tabung A digunakan sebagai blangko, tabung B direaksikan dengan larutan besi (III) klorida 10\%, warna biru tua atau hitam kehijauan menunjukkan adanya tanin dan polifenol, sedangkan pada tabung $\mathrm{C}$ hanya ditambahkan garam gelatin. Apabila terbentuk endapan pada tabung $\mathrm{C}$ maka larutan ekstrak positif mengandung tannin (Chandrashekar, 2012).

\section{Pemeriksaan Glikosida}

Serbuk simplisia uji dilarutkan dalam pelarut etanol, diuapkan diatas tangas air, larutkan sisanya dengan $5 \mathrm{~mL}$ asam asetat anhidrat, ditambahkan 10 tetes asam sulfat . Terjadi endapan warna biru atau hijau menunjukkan adanya glikosida (Reaksi Lieberman-Burchard) (Depkes RI, 1989).

\section{Pemeriksaan Steroid dan Triterpenoid}

Pemeriksaan steroid dan triterpenoid dilakukan dengan reaksi Lieberman-Burchard. Sebanyak $2 \mathrm{~mL}$ larutan uji diuapkan dalam cawan penguap. Residu dilarutkan dengan 0,5 $\mathrm{mL}$ kloroform, tambahkan $0,5 \mathrm{~mL}$ asam asetat anhidrat. Selanjutnya ditambahkan $2 \mathrm{~mL}$ asam sulfat pekat melalui dinding tabung. Terbentuknya cicin kecoklatan atau violet pada perbatasan larutan menunjukkan adanya triterpenoid, sedangkan bila muncul cincin biru kehijauan menunjukkan adanya steroid.

\section{HASIL DAN PEMBAHASAN}

\section{Ekstraksi Serbuk Batang Kepuh (Sterculia foetida $L$.)}

Proses ekstraksi yang dilakukan sebanyak 2 kali remaserasi menghasilkan rendemen sebesar $15,39 \%$ dari 100 gram serbuk dengan 100 mililiter etanol $70 \%$. Dengan demikian rendemen yang dihasilkan telah memenuhi kriteria jumlah rendemen yaitu tidak kurang dari 10\% (Depkes RI, 1978).

\section{Pemeriksaan karakteristik Ekstrak Pemeriksaan Organoleptis}

Ekstrak batang kepuh memiliki bau yang khas dan memiliki warna coklat kehitaman. Tujuan dilakukannya pemeriksaan organoleptis yaitu untuk mengetahui karakteristik ekstrak secara visual. Uji organoleptis merupakan uji indera atau uji sensori sendiri dengan menggunakan indera manusia sebagai alat utama untuk pengukuran daya penerimaan terhadap produk. 


\section{Pemeriksaan Kadar Air}

Ekstrak batang kepuh telah memenuhi persyaratan kadar air untuk ekstrak kental tidak lebih dari $10 \%$ (Depkes RI, 1978) yaitu sebesar 8,66 $\pm 0,748 \%$. Kadar air merupakan banyaknya air yang terkandung dalam bahan yang dinyatakan dalam persen. Kadar air juga salah satu karakteristik yang sangat penting pada bahan pangan, karena air dapat mempengaruhi penampakan, tekstur, dan cita rasa pada bahan pangan. Kadar air dalam bahan pangan ikut menentukan kesegaran dan daya awet bahan pangan tersebut. Kadar air yang tinggi mengakibatkan mudahnya bakteri, kapang, dan khamir untuk berkembang biak, sehingga akan terjadi perubahan pada bahan pangan (Winarno, 1997).
Penetapan kadar sisa pelarut dilakukan dengan metode destilasi, menghasilkan bobot jenis 1.005 dan kadar etanol 0 (nol). Tujuan dilakukan penetapan kadar sisa pelarut yaitu untuk mengetahui sisa pelarut yang masih ada dalam ekstrak setelah dilakukan proses ekstraksi. Tingginya kadar pelarut didalam ekstrak dapat menyebabkan buruknya hasil pemisahan senyawa (Winarno, 1997).

\section{Skrining Fitokimia}

Uji fitokimia digunakan untuk mengetahui golongan senyawa kimia yang terkandung dalam ekstrak etanol $70 \%$ batang kepuh. Hasil skrining fitokimia ekstrak batang kepuh tersebut dapat dilihat pada tabel 1 .

\section{Penetapan Kadar Sisa Pelarut}

Tabel 1. Hasil Skrining Fitokimia Ekstrak Etanol $70 \%$ Batang Kepuh (Sterculia foetida L.)

\begin{tabular}{|l|l|l|}
\hline Pereaksi & Perubahan warna & Kesimpulan \\
\hline Liebermann Burchard & Merah keunguan & $(+)$ steroid dan triterpenoid \\
\hline Asam borat + asam oksalat & Kuning intensif & $(+)$ flavonoid \\
\hline Mayer + Dragendroff & - & $(-)$ alkaloid \\
\hline Akuades + $\mathrm{HCl} 2 \mathrm{~N}$ & Terbentuk busa & $(+)$ saponin \\
\hline $\mathrm{FeCl}_{3} 1 \%$ & Hitam kehijauan & $(+)$ tanin dan polifenol \\
\hline Asam asetat + asam sulfat & - & $(-)$ glikosida \\
\hline
\end{tabular}

Uji fitokimia terhadap ekstrak etanol $70 \%$ batang kepuh menunjukkan hasil positif adanya senyawa golongan steroid, triterpenoid, flavonoid, saponin, tanin dan polifenol, tetapi tidak menunjukkan hasil positif untuk glikosida dan alkaloid. Batang kepuh mengandung senyawa triterpenoid, dan steroid. Berdasarkan uji kualitatif, perubahan warna golongan triterpenoid sangat kuat dengan pereaksi fitokimia. Sehingga senyawa triterpenoid merupakan kandungan utama dalam daun kepuh. Menurut penelitian sebelumnya, Rika (2009) bahwa pada kulit batang Kepuh (Sterculia foetida L.) ditemukan senyawa golongan triterpenoid yang aktif sebagai antiradikal bebas dengan persentase peredaman setelah 5 menit sebesar 76,96\% dan peredaman setelah 1 jam sebesar $99,91 \%$. Senyawa metabolit sekunder yang terdapat dalam tumbuhan biasanya tersebar merata ke seluruh bagian tumbuhan tetapi dalam kadar yang berbeda-beda (Santoso, 2011). Senyawasenyawa golongan triterpenoid diketahui memiliki aktivitas fisiologis tertentu, seperti antijamur, antibakteri, antivirus, kerusakan hati, gangguan menstruasi, dan dapat mengatasi penyakit diabetes (Robinson, 1995).

Dilihat dari uji busa yang dilakukan, ekstrak etanol $70 \%$ batang kepuh menghasilkan busa, dengan demikian ekstrak etanol $70 \%$ batang kepuh menunjukkan reaksi positif adanya senyawa saponin. Adanya senyawa saponin yaitu dinyatakan bahwa batang kepuh memiliki khasiat sebagai antibakteri atau antimikroba. Batang kepuh positif mngandung flavonoid, dipertegas pada penelitian Ika (2017) menunjukkan kepuh memiliki kandungan senyawa flavonoid menggunakan uji KLT yang berungsi sebagai antioksidan. Adanya senyawa tanin dan 
polifenol pada batang kepuh juga memiliki khasiat sebagai antioksidan (Robinson, 1995; Zulviyati, 2016).

\section{Identifikasi dengan spektrofotometri UV-Vis}

Spektrum spektrofotometri UV-Vis dari ekstrak batang kepuh dalam etanol dapat dilihat pada Gambar 1, sedangkan untuk panjang gelombang absorbsi dan absorbansinya dipaparkan pada Tabel 2 .

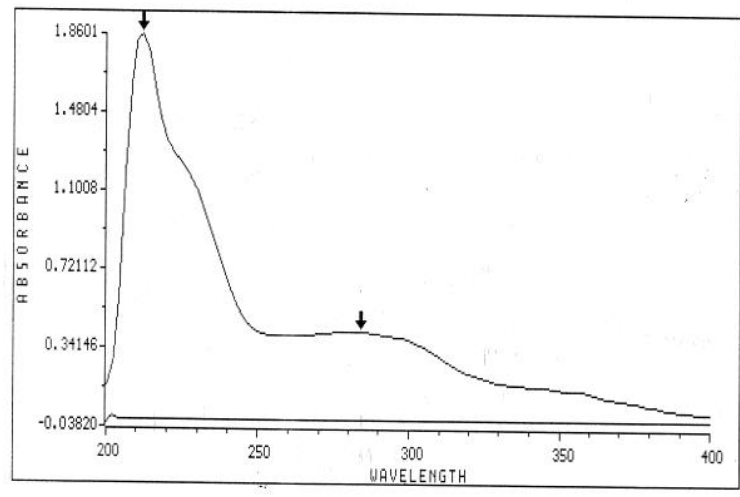

Gambar 1. Spektrum UV-Vis ekstrak kepuh

Tabel 2. Data panjang gelombang dan absorbansi adanya triterpenoid

\begin{tabular}{|c|c|}
\hline $\begin{array}{l}\text { Panjang gelombang } \\
(\mathrm{nm})\end{array}$ & Absorbansi \\
\hline 212 & 1.8601 \\
\hline 284 & 0.42186 \\
\hline
\end{tabular}

Analisis dengan spektrofotometri UVVis diperoleh spektrum dengan dua puncak utama yang muncul pada panjang gelombang $212 \mathrm{~nm}$ sebagai $\lambda$ maks dan puncak yang lain berupa bahu pada panjang gelombang $284 \mathrm{~nm}$. Berdasarkan data spektrum UV-Vis (gambar 4.1), diduga jenis transisi yang terjadi pada panjang gelombang $212 \mathrm{~nm}$ kemungkinan diakibatkan oleh terjadinya transisi elektronik dari $n-\sigma^{*}$ dari kromofor $C=O$. Serapan yang landai pada panjang gelombang $284 \mathrm{~nm}$ kemungkinan diakibatkan oleh terjadinya transisi elektronik $n-\pi^{*}$ dari ikatan rangkap $\mathrm{C}=\mathrm{O}$. Serapan yang landai pada panjang gelombang $284 \mathrm{~nm}$ kemungkinan diakibatkan oleh terjadinya transisi elektronik $n-\pi^{*}$ dari ikatan rangkap $\mathrm{C}=\mathrm{O}$. Dugaan ini diperkuat oleh data dari spektrum inframerah.

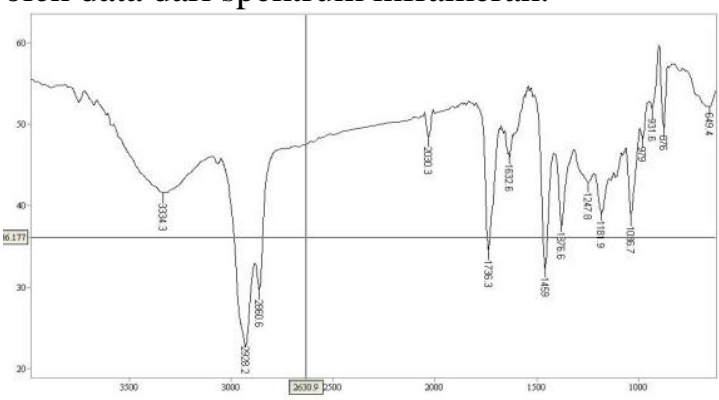

Gambar 2. Spektrum Inframerah ekstrak batang kepuh

Tabel 3. Data spektrum spektrofotometri inframerah (bilangan gelombang, bentuk pita, intensitas, dan penempatan gugus terkait)

\begin{tabular}{|c|c|c|c|c|}
\hline \multicolumn{2}{|c|}{$\begin{array}{l}\text { Bilangan gelombang } \\
\qquad\left(\mathrm{cm}^{-1}\right)\end{array}$} & \multirow[t]{2}{*}{$\begin{array}{c}\text { Bentuk } \\
\text { pita }\end{array}$} & \multirow[t]{2}{*}{ Intensitas } & \multirow[t]{2}{*}{ Penempatan gugus terkait } \\
\hline Pengamatan & Literatur & & & \\
\hline 3334,3 & $3400-2400$ & lebar & sedang & -OH terikat (stretching) \\
\hline 2928,2 & $2960-2870$ & tajam & kuat & $-\mathrm{CH}$ alifatik $\left(-\mathrm{CH}_{3}\right.$ stretching $)$ \\
\hline 2860,6 & $2960-2870$ & tajam & kuat & $-\mathrm{CH}$ alifatik (- $\mathrm{CH}_{2}$ stretching) \\
\hline 1736,3 & $1820-1600$ & tajam & kuat & $-\mathrm{C}=\mathrm{O}$ asam karboksilat \\
\hline 1632,6 & $1650-1500$ & tajam & lemah & $-\mathrm{C}=\mathrm{C}$ alifatik (stretching) \\
\hline 1459 & $1500-1400$ & tajam & kuat & $-\mathrm{CH}$ alifatik (- $\mathrm{CH}_{2}$ bending) \\
\hline 1376,6 & $1500-1400$ & tajam & sedang & $-\mathrm{CH}$ alifatik $\left(-\mathrm{CH}_{3}\right.$ bending $)$ \\
\hline 1247,8 & $1300-1000$ & tajam & sedang & -C-O alkohol (bending) \\
\hline 979 & $1000-650$ & tajam & lemah & $\mathrm{CH}$ alkena (bending) \\
\hline
\end{tabular}


Berdasarkan data spektrum inframerah diperoleh serapan melebar pada daerah bilangan gelombang $3334,3 \mathrm{~cm}^{-1}$ adalah serapan $\mathrm{OH}$ stretching terikat dan didukung adanya serapan pada dearah bilangan gelombang $1247,8 \mathrm{~cm}^{-1}$ yang diduga serapan C-O. Pita serapan pada daerah bilangan gelombang 2928,2 $\mathrm{cm}^{-1}$ dan 2860,6 $\mathrm{cm}^{-1}$ adalah serapan untuk $\mathrm{CH}$ alifatik $\left(\mathrm{CH}_{3}\right.$ dan $\mathrm{CH}_{2}$ stretching) yang didukung adanya serapan pada daerah bilangan gelombang $1459 \mathrm{~cm}^{-1}$ dan 1376,6 $\mathrm{cm}^{-1}$ yang diduga serapan $\mathrm{CH}_{2}$ bending dan $\mathrm{CH}_{3}$ bending. Pita serapan pada daerah bilangan gelombang $1736,3 \mathrm{~cm}^{-1}$ menunjukkan adanya gugus $\mathrm{C}=\mathrm{O}$ yang didukung dengan adanya serapan pada dearah bilangan gelombang $1247,8 \mathrm{~cm}^{-1}$ yang diduga serapan C-O. Adanya serapan melebar $\mathrm{OH}$ dan didukung serapan tajam $\mathrm{C}=\mathrm{O}$ yang merupakan ciri khas dari asam karboksilat. Pita serapan pada daerah bilang gelombang 1632,6 $\mathrm{cm}^{-1}$ terdapat $\mathrm{C}=\mathrm{C}$ alifatik stretching yang didukung oleh serapan pada bilangan gelombang $979 \mathrm{~cm}^{-1}$ yang diduga serapan $\mathrm{CH}$ alkena.

Berdasarkan data-data tersebut maka diduga ekstrak batang kepuh mempunyai gugus fungsi $-\mathrm{OH}, \mathrm{CH}$ alifatik, $\mathrm{C}=\mathrm{O}, \mathrm{C}=\mathrm{C}$ alifatik, dan C-O. Dari data dengan spektrum UV-Vis, inframerah ekstrak kepuh diduga positif mengandung senyawa triterpenoid

\section{SIMPULAN DAN SARAN}

\section{Simpulan}

Ekstrak etanol $70 \%$ batang kepuh (Sterculia foetida L.) telah memenuhi standar ekstrak simplisia dilihat dari hasil pemeriksaan karakteristik ekstrak. Skrinng fitokimia menunjukkan ekstrak etanol $70 \%$ batang kepuh mengandung senyawa steroid, triterpenoid, flavonoid, saponin, tanin dan polifenol. Pada identifikasi menggunakan spektrofotometri UV-Vis menghasilkan $\lambda 212$ sebesar 1,8601 dan $\lambda 284$ sebesar 0,42186 serta dari data spektrum inframerah positif mengandung senyawa triterpenoid.

\section{Saran}

Perlu dilakukan pemisahan menggunakan kromatografi kolom untuk memastikan senyawa yang terkandung dari ekstrak batang kepuh ditinjau dari hasil skrining fitokimia ekstrak etanol $70 \%$ batang kepuh.

\section{UCAPAN TERIMAKASIH}

Terimakasih penulis ucapkan untuk seluruh staf dosen, pegawai Fakultas Matematika dan Ilmu Pengetahuan Alam, Universitas Udayana.

\section{DAFTAR PUSTAKA}

Chandrashekar, R. and Rao, S.N. (2012). Phytochemical Analysis of Ethanolic Extract of Leaves of Clerodendrum viscosum (EELCV). World J Pharm and Pharm Sci, Vol. 1 (3): 1092-1099.

Depkes RI. 1978. Materia Medika Indonesia. Jakarta: Departemen Kesehatan Republik Indonesia.

Depkes RI. 1989. Sediaan Galenik. Jakarta: Departemen Kesehatan Republik Indonesia.

Depkes RI. 1995. Farmakope Indonesia. Edisi IV. Jakarta: Departemen Kesehatan Republik Indonesia.

Depkes RI. 2000. Parameter Standar Umum Ekstrak Tumbuhan Obat. Jakarta: Direktorat Jendral Pengawasan Obat dan Makanan.

Farnsworth, N. R., 1966, Biological and Phytochemical Screening of Plants, Journal of Pharmaceutical Sciences, 55 (3).

Heyne, K. 1987. Tumbuhan Berguna Indonesia III, terjemahan: Badan Penelitian dan Pengembangan Kehutanan. Jakarta : Yayasan Sarana Wana Jaya.

Herdiana N.2005 . Potensi Budidaya Kepuh (Sterculia Foetida Linn). Proseding Hasil-Hasil Penelitian Hutan Tanaman Baturaja.

Ika R.S, Rasyada I,Yuniar A, 2017. Aktivitas Antihiperlipidemi dan Ateroprotektif Ekstrak Etanol Daun Kepuh (Sterculia foetida) pada Tikus yang Diinduksi Diet Tinggi Lemak. Journal of Agromedicine and Medical Sciences. 3(1).

Khoiraini, N. 2013. Karakterisasi Simplisia dan Standarisasi Ekstrak Etanol Herba Kemangi (Ocimum americanum L.). 
Skripsi. Jakarta: UIN Syarif Hidayatullah Jakarta.

Maryanti, A dan R. L. Hendarti. 2014. Budidaya Kepuh (Sterculia foetida L.) Untuk Antisipasi Kondisi Kering. Bogor: IPB IPP Press.

Rika, K. D., 2009, Isolasi Dan Identifikasi Golongan Senyawa Aktif Antiradikal Bebas Dari Kulit Batang Kepuh (Sterculia foetida L.), Skripsi, Jurusan Kimia, FMIPA, Universitas Udayana, Denpasar.

Robinson, T., 1995, Kandungan Organik Tumbuhan Tinggi, a.b Padmawinata, K, edisi ke-6, ITB, Bandung.

Santoso, B. 2011. Pemberian IBA (indole butyric acid) dalam Berbagai Konsentrasi dan Lama Perendaman terhadap Pertumbuhan Stek Kepuh (Sterculia foetida linn). Skripsi. Surakarta: Universitas Sebelas Maret.
Suwandi, Maryanti.A. 2013. Pertumbuhan Bibit Kepuh (Sterculia Foetida Linn) Umur 4 Bulan di Pesemaian. Informasi Teknis, 11(1), B2 PBPTH.

Winarno, F.G. 1991. Kimia Pangan dan Gizi. Gramedia; Jakarta.

Zulviyati, Siswoyo, T.A., Puspitasari, E. 2016. Uji Aktivitas Antioksidan dan Antihiperlipidemia Ekstrak Daun Kepuh (Sterculia foetida): Metode DPPH dan Hambatan Lipase in Vitro. Skripsi. 